\title{
ARES-I BENDING FILTER DESIGN USING A CONSTRAINED OPTIMIZATION APPROACH
}

\author{
Jiann-Woei Jang ${ }^{1}$, Robert Hall ${ }^{2}$, Nazareth Bedrossian ${ }^{3}$ \\ The Charles Stark Draper Laboratory, Inc \\ Charles Hall ${ }^{4}$ \\ NASA Marshall Space Flight Center
}

\begin{abstract}
The Ares-I launch vehicle represents a challenging flex-body structural environment for control system design. Software filtering of the inertial sensor output is required to ensure adequate stable response to guidance commands while minimizing trajectory deviations. This paper presents a design methodology employing numerical optimization to develop the Ares-I bending filters. The design objectives include attitude tracking accuracy and robust stability with respect to rigid body dynamics, propellant slosh, and flex. Under the assumption that the Ares-I time-varying dynamics and control system can be frozen over a short period of time, the bending filters are designed to stabilize all the selected frozen-time launch control systems in the presence of parameter uncertainty. To ensure adequate response to guidance command, step response specifications are introduced as constraints in the optimization problem. Imposing these constrains minimizes performance degradation caused by the addition of the bending filters. The first stage bending filter design achieves stability by adding lag to the first structural frequency to phase stabilize the first flex mode while gain stabilizing the higher modes. The upper stage bending filter design gain stabilizes all the flex bending modes. The bending filter designs provided here have been demonstrated to provide stable first and second stage control systems in both Draper Ares Stability Analysis Tool (ASAT) and the MSFC MAVERIC 6DOF nonlinear time domain simulation.
\end{abstract}

\footnotetext{
${ }_{1}^{1}$ Senior Member Technical Staff ; Draper Laboratory, Houston TX, 77058: jjang@draper.com

${ }^{2}$ Principal Member Technical Staff; Draper Laboratory, Huntsville, AL 35812: Robert.A.Hall@nasa.gov

${ }^{3}$ Group Leader, Manned Space Systems; Draper Laboratory, Houston TX, 77058: naz@draper.com

${ }^{4}$ Senior Aerospace Engineer; NASA Marshall Space Flight Center, Huntsville, AL 35812:Charles.E.Hall@nasa.gov
} 


\section{Introduction}

The Ares-I vehicle has several characteristics which must be taken into account. First, it is aerodynamically unstable because the vehicle's center of pressure is above its center of gravity. Second, the vehicle's mass, moment of inertia, aerodynamics, slosh, and bending characteristics vary greatly throughout the launch timeline as shown in Figure 1. Third, Ares-I's unique long cylindrical body and low structural mass are sources of significant flexible body dynamics. The large flex response in the feedback loop may cause control structure interaction and eventually result in instability if excessive control gain and incorrect phasing are presented.

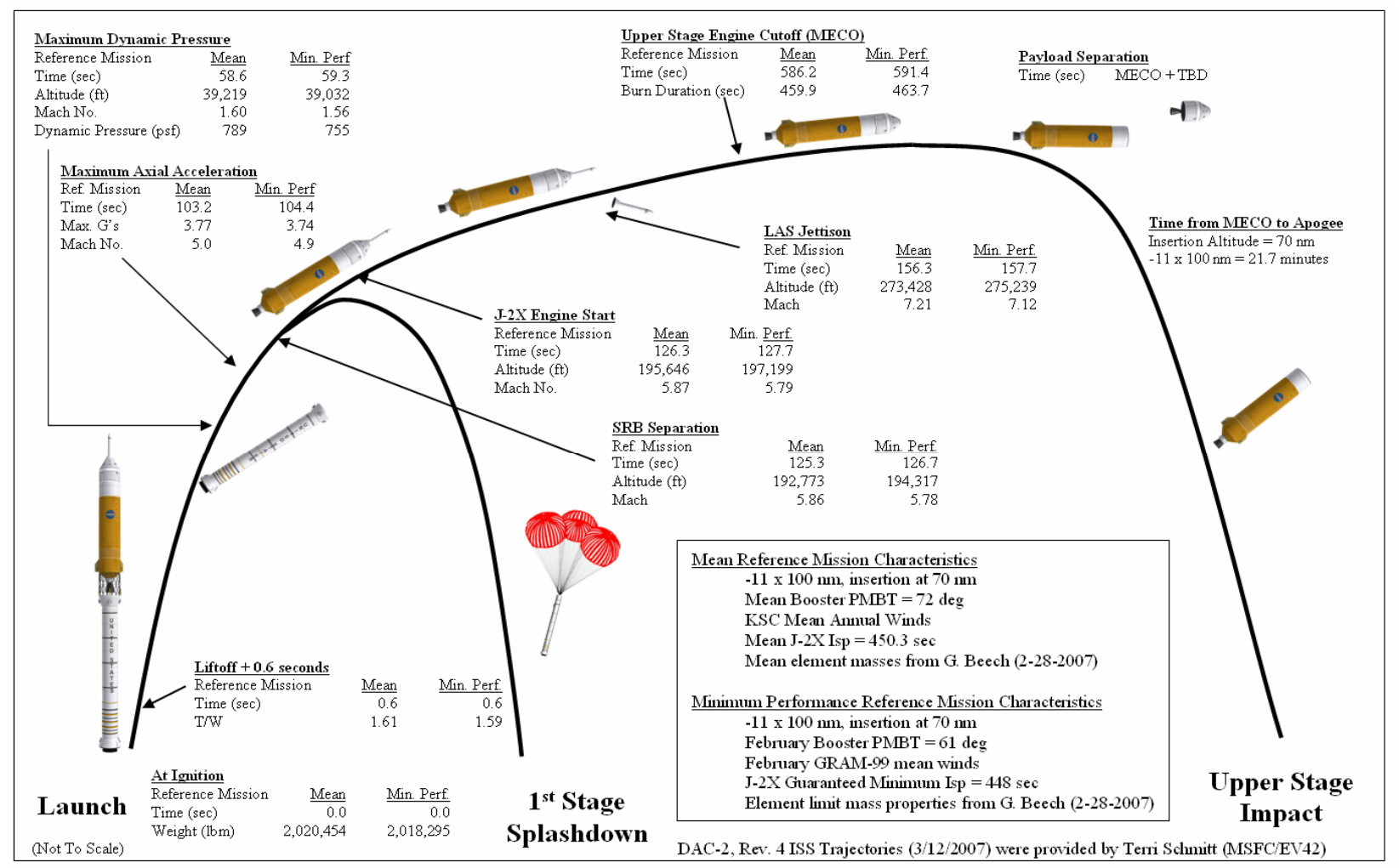

Figure 1. Representative Design Analysis Cycle (DAC) 2 Rev4 Trajectory Profile (ISS Missions)

To achieve desired performance and guaranteed robust stability for the Ares-I control system, the control design can be divided into four phases: (1) Optimal rigid performance control system designs, which include a phase plane controller for roll channel and PID controller for pitch and yaw channels, (2) Sensor blending selection to reduce flex response [1], (3) Flex filter design to guarantee robust stability and performance and (4) High fidelity nonlinear simulation to verify stability and performance of the overall Ares-I control system. These four design phases are not 
necessarily performed in sequence. For example, flex filter and PID control designs can be combined into an iterative design phase. Due to the length constraint of this paper, only the filter design will be described; PID control gains and sensor location are assumed given and will be detailed in a later section.

Digital filter designs and application have been extensively investigated in the literature [2][4]. The most popular analog filter design approaches include Butterworth, Chebyshev and elliptic filters [2][4]. Direct digital filter design methodologies are also available in the literature [3]. These methodologies have been used for open-loop system designs by shaping filters to meet the open-loop performance specifications in the frequency domain. Unfortunately, most of the closed-loop system stability/performance requirements cannot be directly mapped into open-loop system specifications. A multivariable control system design algorithm demonstrates the feasibility of including the closed-loop system stability requirement in the filter design process for a launch vehicle at one flight time [5].

In the past three decades, engineers and mathematicians have devoted their efforts to developing modern control theory, which utilizes optimization processes to determine the filter/controller designs that provide the best closed-loop performance according to different system metrics. For example, the $\mathrm{H}_{2}$ control method minimizes the 2-norm of the closed-loop system and the $\mathrm{H}_{\infty}$ control method generates the optimal filter based on the minimum of the maximum closed-loop singular value. An optimal filter design using $\mathrm{H}_{2}$ control method has demonstrated significant better performance for the Saturn launch vehicle [6]. The design variables for the both methods are shaping filter; however, selecting the optimal filters to simultaneously achieve stability and performance requirements is still a difficult task. The constrained $\mathrm{H}_{2}$ optimization method [7]-[10] expands the design space by including the closedloop stability margin requirements. In order to preserve the convexity of the problem, the infinite-dimensional Youla parameterization is approximated by a finite number of orthogonal basis functions. Typical orthogonal basis functions include the FIR, Laguerre, and GOBF [10]. The orthogonality of these basis functions may limit its application space. For example, all the orthonormal basis functions either have no zeros or pole dependent zeros in their filter architecture. Recently, a robust controller design methodology was proposed using a numerical constrained optimization approach to maximize stability margins while meeting performance requirements [11]-[15]. This control design methodology has been successfully used to design a single robust control moment gyro (CMG) flex filter set for multiple International Space Station (ISS) stages [11] and robust flex filters and a PID controller for the Orbiter Repair Maneuver operation [13]. The similar design procedure has applied to an initial Ares-I bending filter design which meets nominal stability margin requirements throughout the first stage flight. [15] 
This paper addresses the Ares-I control system/structural dynamic interaction problem, the use of constrained optimization for filter development, stability and margin requirements definition, and time domain performance demonstration. The design objectives include attitude tracking accuracy and robust stability of rigid vehicles, propellant slosh, and flex. The first stage bending filter design achieved stability by adding lag to the first structural frequency, thereby phase stabilizing the first flex mode while gain stabilizing the higher modes. The upper stage bending filter design gain stabilizes all flex modes. Gain stabilization of a flexible mode refers to a filter design where the flex mode amplitude is attenuated to an extent to not cause a stability concern. Phase stabilization of a flexible mode refers to a filter design where the phasing of the first mode does not cause a stability concern. In the latter case, the control system may actively damp the structure flexure. The bending filter designs provided here have been demonstrated to provide stable first and second stage control systems in Draper Ares Stability Analysis Tool (ASAT) [16] and will be verified in the MSFC MAVERIC 6DOF nonlinear time domain simulation.

\section{Ares-I Control System}

The Ares-I launch vehicle uses a single five-segment solid rocket booster for the first stage, a derivative of the space shuttle's solid rocket booster. A liquid oxygen/liquid hydrogen J-2X engine derived from the J-2 engine used on Apollo's second stage will power second stage. First stage control is accommodated by Thrust Vector Control (TVC) for the pitch and yaw axes and Reaction Control System (RCS) for the roll axis. Based on the fact that vehicle flexibility in the roll channel is not significant [17][18], only the pitch/yaw attitude control system in the first and upper stage of the ascent flight is considered in this paper. Because of the symmetry of the vehicle and small cross coupling, pitch and yaw attitude control systems are assumed identical [17][18].

The Ares-I attitude control system model as shown in Figure 2 includes the Ares-I dynamics and attitude-hold controller modules. The Ares-I dynamics modules consist of both rigid and flex dynamics models [17][18]. The dynamics modules take in actual gimbal angles and output attitude and rate gyro measurements. The blended attitude and rate error signals represent the difference between commanded and actual attitude and rate. They are filtered by the attitude and rate filters, respectively. The filtered error signals are sent to the PID controller as shown in Figure 2 to generate the commanded gimbal angles, which drive the gimbal dynamics [19]. The rate blending option can be used to actively reduce structural flexibility and the attitude blending option can be used to adjust vehicle performance. 


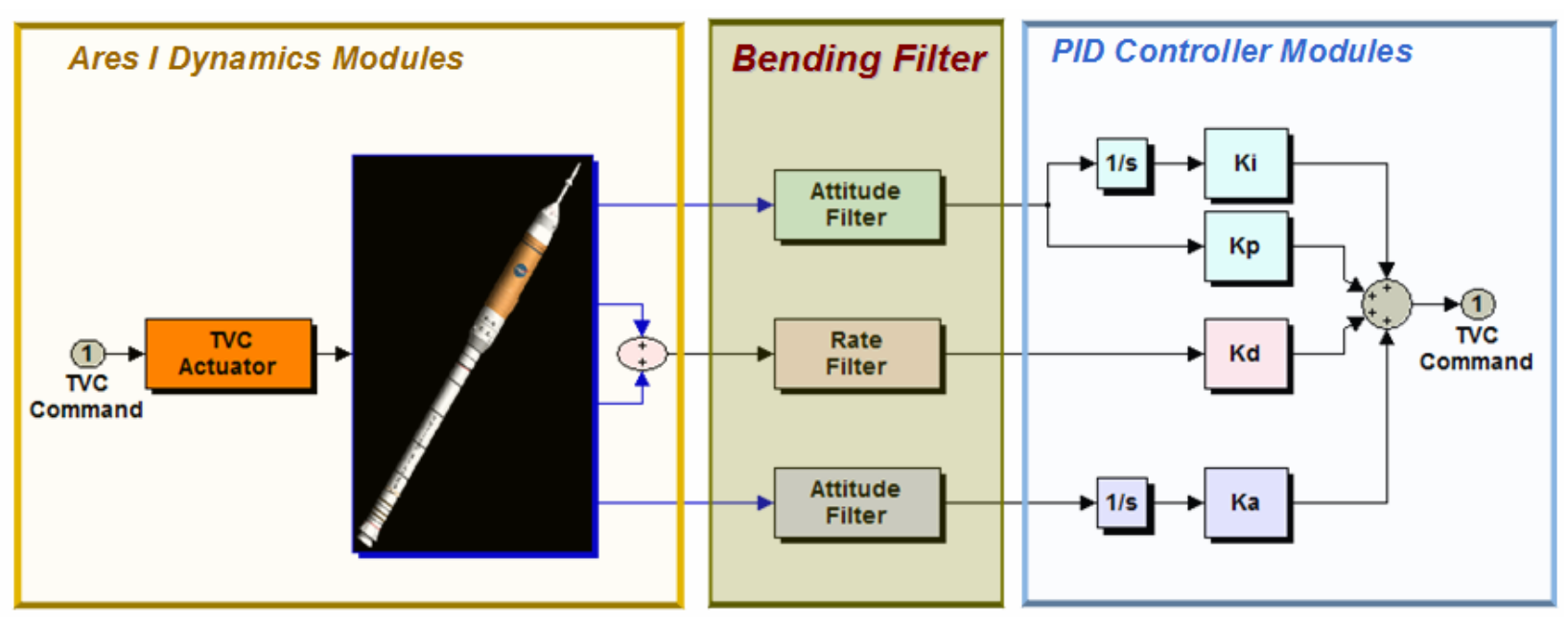

Figure 2. Ares-I Attitude Control System Model

The Ares-I vehicle mass properties, flexibility, and aerodynamics characteristics vary drastically throughout the entire ascent flight [20]. To ensure both robust stability margins and flex stability under such variations, the Ares-I attitude hold controller was designed using a piecewise linear approximation approach. The fundamental assumption is that the dynamics are "frozen" over a short period of time [21]. In this way, linear time invariant control techniques can be used to design and analyze the Ares-I control system. Finally, the design is verified via nonlinear time varying simulation.

Both the PID gains and flex filters influence the Ares-I stability margin. With the assumption that the PID gains have been selected for rigid-body performance, the Ares I controller design task can be reduced to determining the bending filter parameters to meet rigid and flex stability margins. The bending filter design procedure is detailed in the next sections.

\section{Constrained Optimization Filter Design}

It has been previously demonstrated in multiple space applications [7]-[14] that bending filters can be designed numerically using a constrained optimization framework. The design parameters are the coefficients of the bending filters. For example, if an $\mathrm{n}^{\text {th }}$ order transfer function architecture is selected for both attitude and rate filter, the total number of design parameters is $4 \mathrm{n}$. 


$$
\begin{aligned}
& F_{\text {attitude }}(s)=\prod_{i=0}^{N-1} \frac{s^{2}+2 x_{4 *_{i+2}} x_{4 *_{i+1}} s+x_{4 *_{i+1}}{ }^{2}}{s^{2}+2 x_{4 *_{i+4}} x_{4 *_{i+3}} s+x_{4 *_{i+3}{ }^{2}}{ }^{2}} \\
& F_{\text {rate }}(s)=\prod_{i=0}^{N-1} \frac{s^{2}+2 x_{4 *_{i+2}} x_{4 *_{i+1}} s+x_{4 *_{i+1}}{ }^{2} s^{2}+2 x_{4 *_{i+4}} x_{4 *_{i+3}} s+x_{4 *_{i+3}}{ }^{2}}{}
\end{aligned}
$$

A set of feasible parameters must satisfy the following constraints:

(C1). The filter itself must be stable and minimal phase to guarantee stability and performance.

(C2). The bandwidth of the bending filter should be greater than that of the PID controller to avoid rigid performance degradation.

These constraints can be used to set the upper and lower bounds for the bending filter design.

The primary objective of Ares-I control system design is to provide sufficient stability margins in the presence of various uncertainties while maintaining adequate system response. The stability margin criteria from [23] are used in this paper:

(O1). The closed-loop Ares-I control system must be robustly stable under mass property, slosh, and atmosphere variation.

$(\mathrm{O} 2)$. At least $6 \mathrm{~dB}$ gain margin and 30 degree phase margin are required for rigid only control system.

(O3). At least $9 \mathrm{~dB}$ gain margin of the peak amplitude is required for gain stabilized bending modes.

(O4). At least 60 degree phase margin is required for phase stabilized bending modes.

To simplify the optimization problem, the objective (O1) is neglected in the design process; it is assumed that if $(\mathrm{O} 2)$ is satisfied, then $(\mathrm{O} 1)$ is guaranteed. The satisfaction of $(\mathrm{O} 1)$ will be verified in the post design analysis. To ensure adequate response to guidance command, constraints derived from step response specifications [23] are imposed in the optimization problem. The additional constraints minimize performance degradation due to the addition of the bending filters. These attitude pointing specifications, which include requirements for rise time, percent overshoot, settling time, and steady state errors, vary during the entire flight time.

The Ares-I control systems must also ultimately demonstrate robustness to uncertainties in the plant. The goal is to design bending filters that are robust to uncertainty in structural frequency, mode shape, mass properties, and aerodynamics characteristics. In this paper, only mass property variation and structural frequency uncertainty are considered. Mass property variation is modeled using frozen time rigid dynamics for flight times at [1 10:10:120] seconds 
for the first stage flight and [130157 158160161 180:50:530 575] seconds for the upper stage flight. Structural uncertainty is modeled via bending mode frequency shift from nominal. Frequency shifts are made at $5 \%$ increments up to $+/-10 \%$ for the first bending mode and $+/$ $30 \%$ for higher modes. In all, a total of 39 and 42 frozen systems $(G)$ are used to represent the first and upper stage flight phases, respectively.

Once design objectives and constraints are identified, the bending filter design task is ready to be cast as the following constrained optimization problem

$$
\begin{array}{cc}
\min _{x \in R^{4 N}, G} & f(x) \\
\text { S.t. } & \\
& g(x) \leq 0 \\
& x_{l} \leq x \leq x_{u}
\end{array}
$$

The filter design criteria (C1) and (C2) can be formulated as inequality constraints. The design objective can be cast either as an inequality constraint $g(x)$ or as an objective $f(x)$ in the above multi-objective constrained optimization problem. In general, these objectives are competing. For example, maximizing gain margins usually diminishes phase margins. Therefore, there is no unique solution to this problem. To address this, Pareto optimality [22] must be applied to characterize the objectives. This is accomplished with a weighted sum strategy, which converts the multi-objective problem into a single objective optimization problem.

\section{Ares-I Filter Design}

Due to the small cross coupling between axes, the planar dynamics derived by Haussermann [14] and Frosh and Vallely [18] are used as a basis for Ares-I bending filter designs. The planar dynamics model includes rigid rotation, lateral translation, slosh, and bending dynamics. All launch vehicle mass properties, trajectory data, aerodynamic coefficients, slosh data, and structural models are supplied by NASA Marshall Space Flight Center. Preliminary Ares-I filter designs will be presented in this section to demonstrate the constrained optimization design methodology.

There are three assumptions made for the bending filter design. First, the attitude control PID gains, are initially designed to meet rigid body performance requirements, i.e. were not part of the initial design trade-off for flex body stability. Second, multiple flex models are defined throughout the Ares-I flight. Each structural model corresponds to a particular flight time and is used until the next flight time for which a different structural model is defined. Third, the blended first stage and upper stage rate gyro measurement with weighting ratio of $80 / 20$ is used 
as the rate signal during the first stage flight, whereas only the instrument unit measurement is used as the rate signal for the upper stage flight.
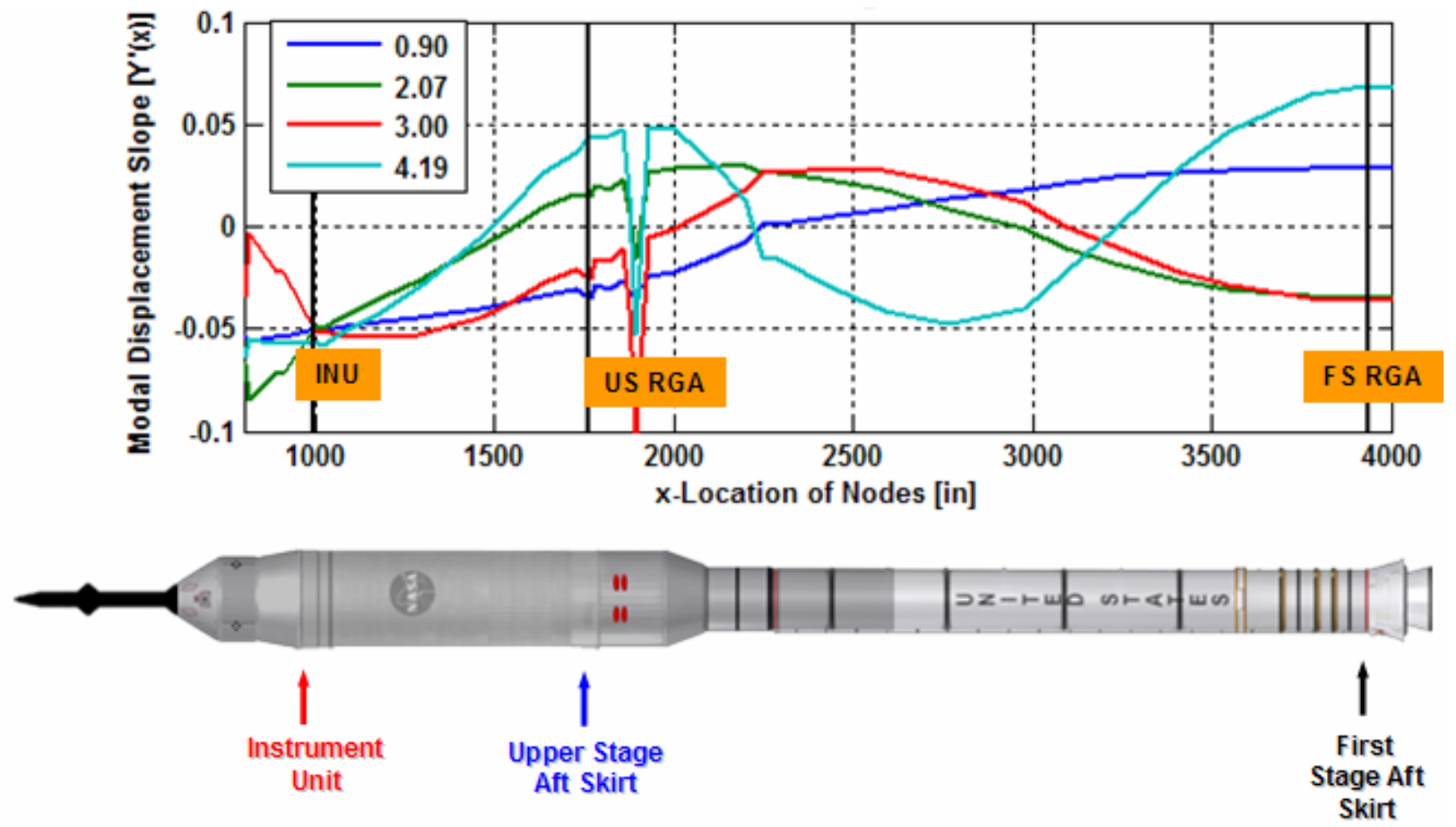

Figure 3. Modal Displacement Slope

First Stage Filter Design:

The Ares-I first stage structural characteristics shown in Figure 4(a) consist of the frequency response of both slosh modes $(\sim 0.5 \mathrm{~Hz})$ and bending modes $(>0.9 \mathrm{~Hz})$. The first bending mode frequency increases from lift-off to the end of Ares-I first stage flight. The smallest first bending mode $(0.9 \mathrm{~Hz})$ of the first stage structural models is very close to the bandwidth $(0.18 \mathrm{~Hz})$ of the first stage PID controller. A gain stabilizing design for the first bending mode may result in control bandwidth reduction and hence performance degradation. Therefore, the first stage bending filter design achieves stability by adding phase lag to the first structural frequency. As the open-loop Nichols charts of the Ares-1 first stage control systems show in Figure 4(b), a candidate filter must provide at least 90 degree phase lag to achieve a desirable phase stability margin. The other filter design objective is gain stabilizing the higher modes. The smallest higher mode for the first stage structural models is about $2.4 \mathrm{~Hz}$; the largest flex plant response of higher modes is about $25 \mathrm{~dB}$. To gain stabilize higher modes, a candidate filter must provide $25 \mathrm{~dB}$ gain attenuation for frequencies greater than $2.4 \mathrm{~Hz}$. 
With the final first stage filter design, which employs $8^{\text {th }}$ order filters in both attitude and rate channels, the Nichols charts of the resulting first stage nominal control systems in Figure 5 demonstrate $6 \mathrm{~dB}$ gain and 30 degree nominal stability margins. The large humps shown in Figure 5 are the frequency responses of the first bending modes, which demonstrate that the control systems possess at least 60 degree flex phase margin for the first bending modes. The curves shown on the left side of those large humps in Figure 5 are the frequency responses of higher bending modes, which demonstrate at least $9 \mathrm{~dB}$ flex gain margins. The Ares-I first stage filter design is verified in ASAT and demonstrates robust stability with $10 \%$ and $30 \%$ flex frequency perturbation of the first and higher bending modes throughout the first stage flight and has minimum $6 \mathrm{~dB}$ gain and 30 degree phase robust stability margins as shown in Figure 6 . The Ares-I first stage filter design will be verified via a high fidelity nonlinear MAVERIC simulation.

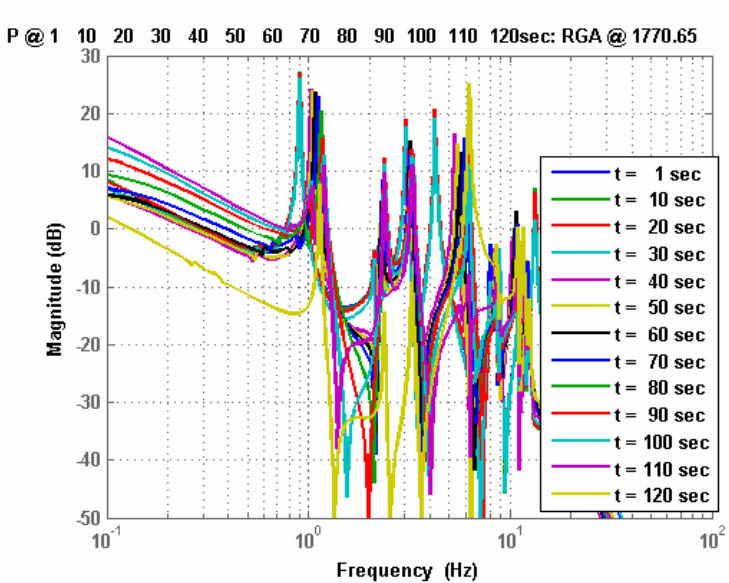

(a)

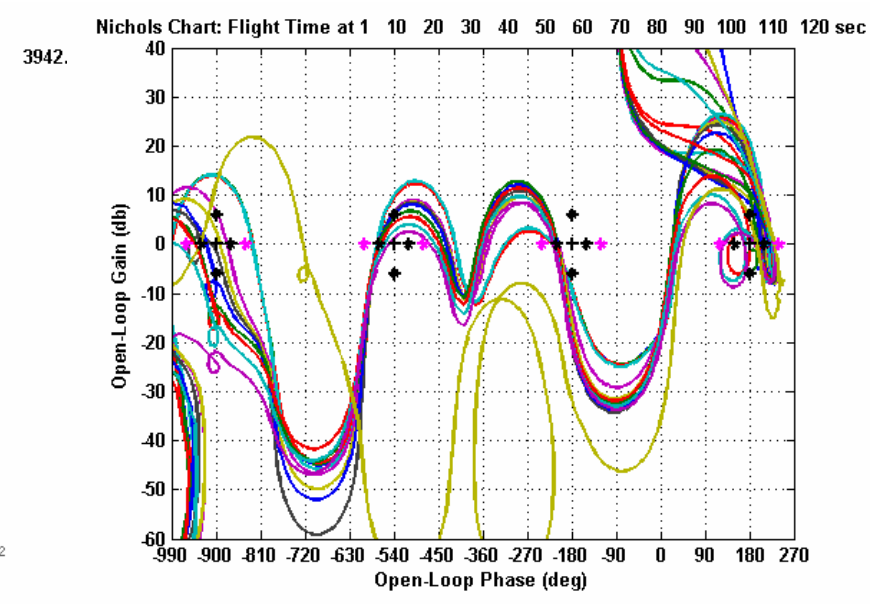

(b)

Figure 4. First Stage Flex Characteristics and Control Systems Without Bending Filters
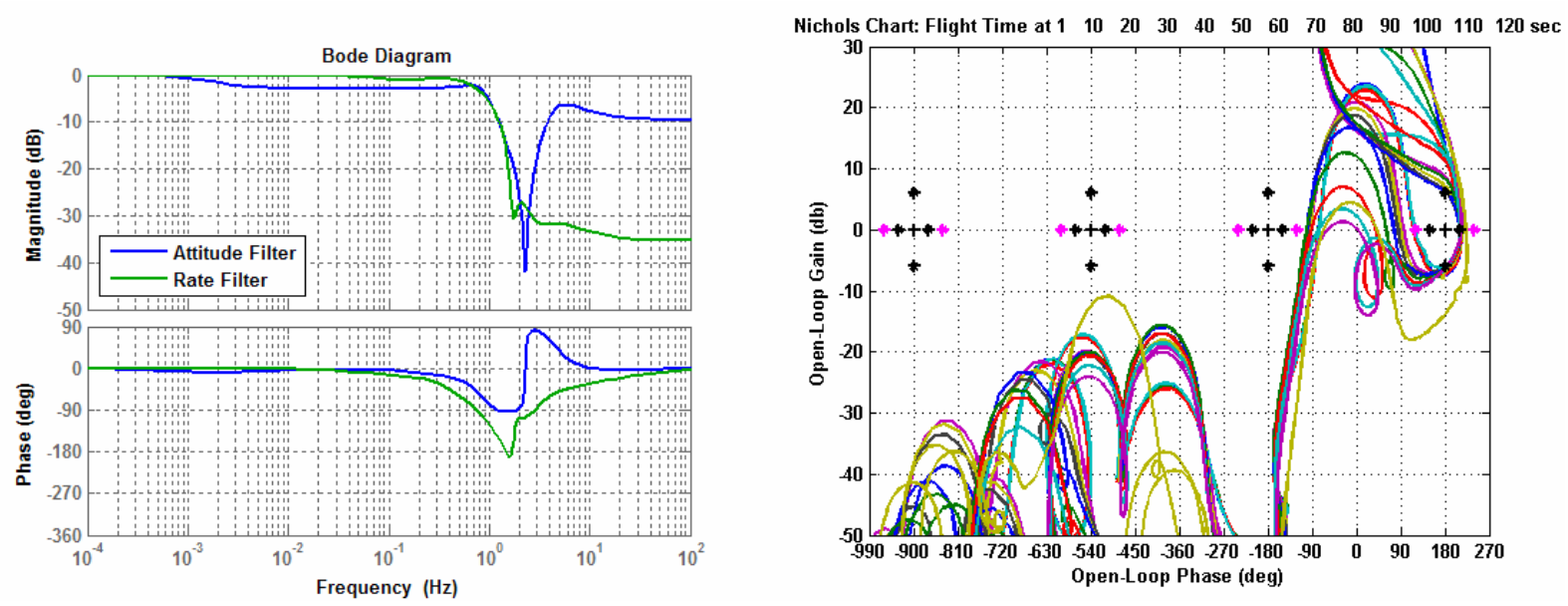

Figure 5. Nichols Chart of First Stage Nominal Control Systems with Final First Stage Filter 
Overall Carpet Plot (Frequency Variation)

First Stage Sensors: 0.8 @ 1771, $0.2 @ 3943$ w/ Attitude Blending @ 1771 Upper Stage Sensors: $1 @ 992$ w/ Attitude Blending @ 992

GM

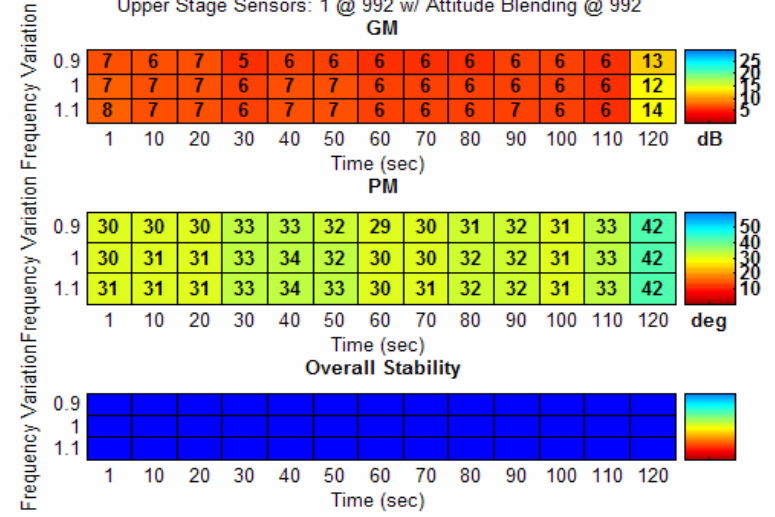

(a)

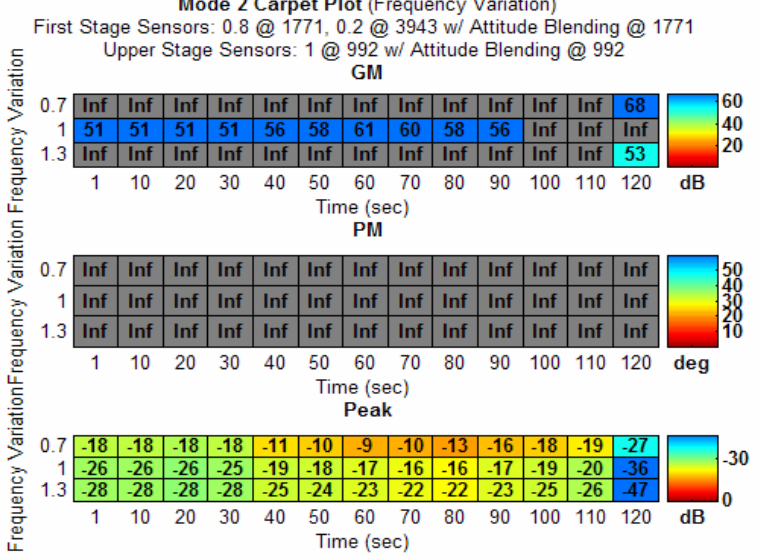

(c)

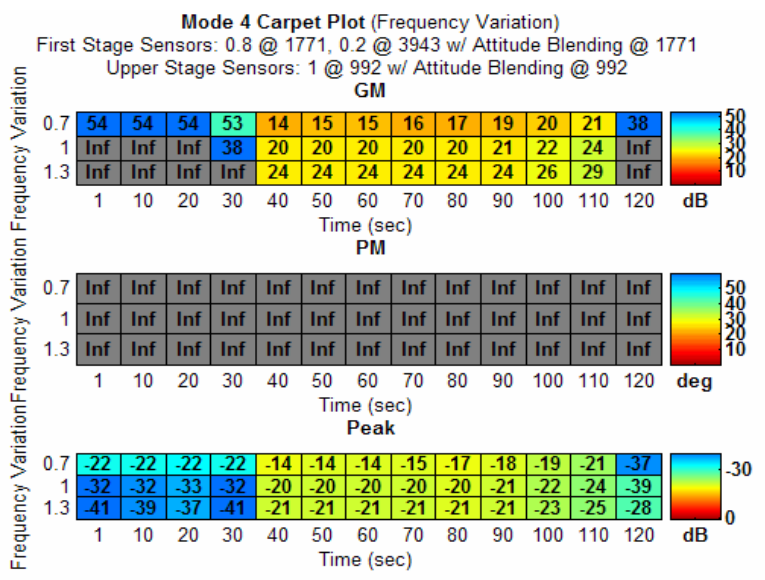

(e)
Mode 1 Carpet Plot (Frequency Variation) First Stage Sensors: $0.8 @ 1771,0.2 @ 3943$ w/ Attitude Blending @ 1771

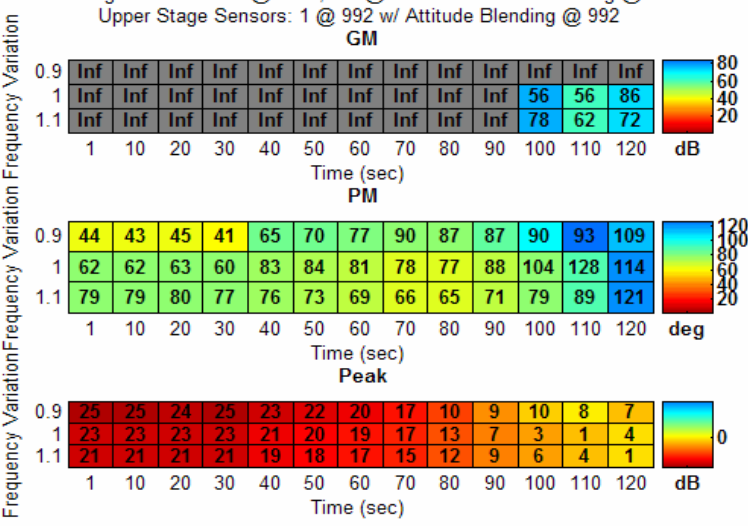

(b)

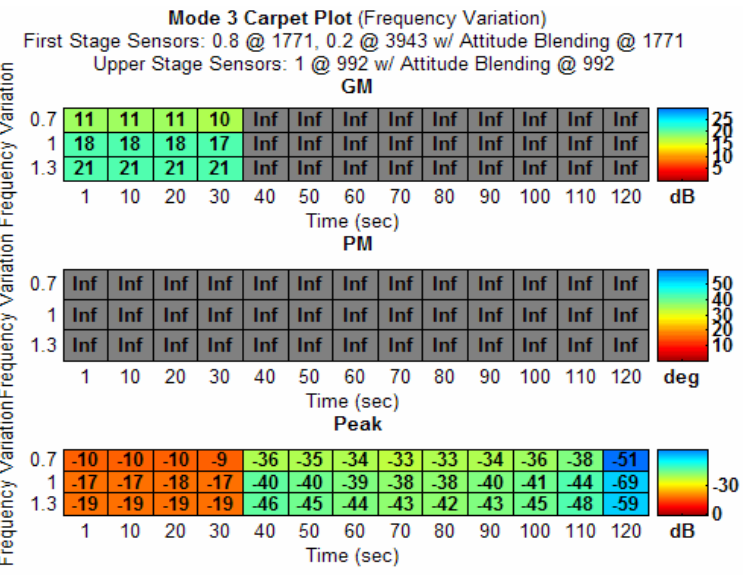

(d)

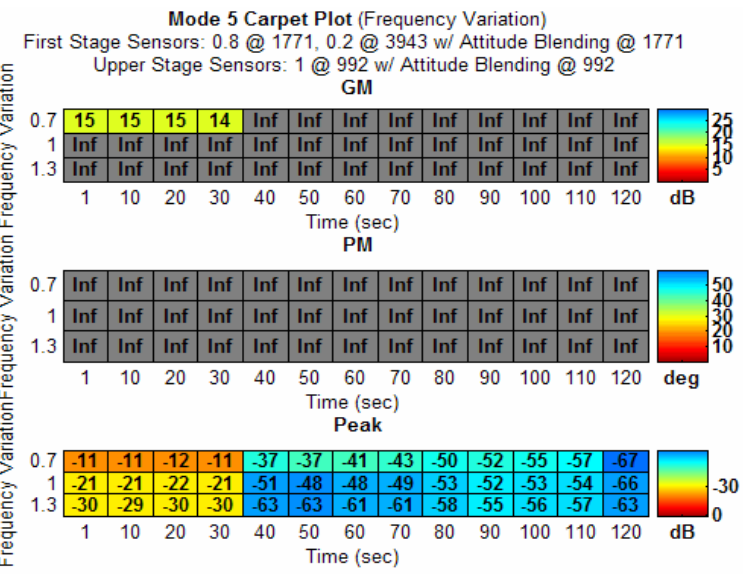

(f)

Figure 6. Robust Analysis Summary of First Stage Control Systems 


\section{Upper Stage Filter Design:}

The upper stage structural characteristics shown in Figure 7(a) consist of frequency responses of both slosh modes $(0.4$ to $0.7 \mathrm{~Hz})$ and flex bending modes $(>2 \mathrm{~Hz})$. The upper stage slosh modes are much stronger than those in the first stage flight, which uses a solid booster only. The dominant flex modes between $2 \mathrm{~Hz}$ and $4 \mathrm{~Hz}$ are associated with the structural models near LAS jettison, and the dominant flex modes larger than $5 \mathrm{~Hz}$ are associated with the structural models after LAS jettison.

The objective for the Ares-I upper stage bending filter design is gain stabilization of all bending modes. As the open-loop Nichols charts of the Ares-1 upper stage control systems show in Figure 7(b), the smallest bending mode of the upper stage structural models is about $2.4 \mathrm{~Hz}$ and the largest flex response is about $13 \mathrm{~dB}$. To gain stabilize the upper stage flex modes, a candidate filter must provide at least $13 \mathrm{~dB}$ gain attenuation for frequencies greater than $2.4 \mathrm{~Hz}$.

As in the final first stage filter design, the final upper stage filter employs $8^{\text {th }}$ order filters in both attitude and rate channels. The Nichols charts of the resulting upper stage control systems in Figure 8 demonstrate $6 \mathrm{~dB}$ gain and 30 degree phase nominal stability margins. The large humps in Figure 8 are frequency responses of those slosh modes, which are phase stabilized. The curves shown on the left side of those large humps in Figure 8 are the frequency responses of flex bending modes, which demonstrate at least $9 \mathrm{~dB}$ flex gain margins. The Ares-I upper stage filter design is verified in ASAT and demonstrates robust stability with $10 \%$ and $30 \%$ flex frequency perturbation of the first and higher bending modes, respectively, throughout the upper stage flight. The design has minimum $6 \mathrm{~dB}$ gain and 30 degree phase robust stability margins as demonstrated in Figure 9. The Ares-I upper stage filter design will be verified via a high fidelity nonlinear MAVERIC simulation. 
chols Chart: Flight Time at $130157 \quad 158 \quad 160 \quad 161 \quad 180 \quad 230 \quad 280 \quad 330 \quad 380 \quad 430 \quad 480 \quad 530 \quad 57$

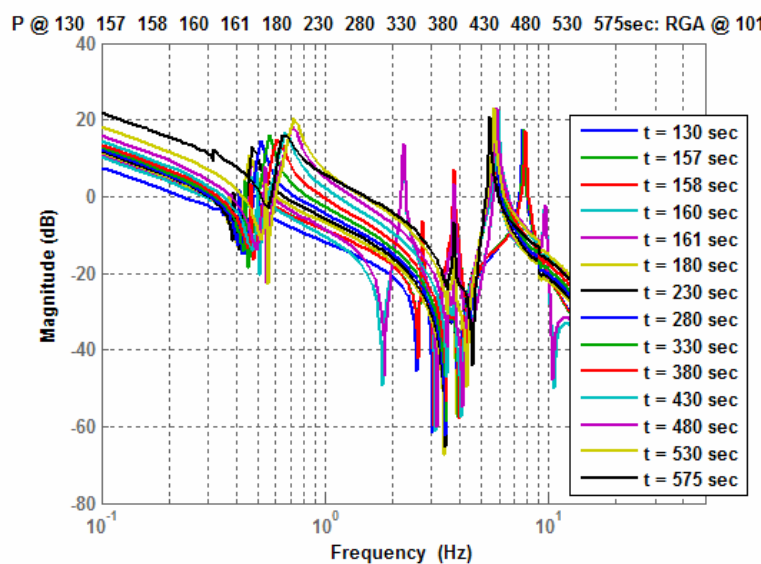

(a)

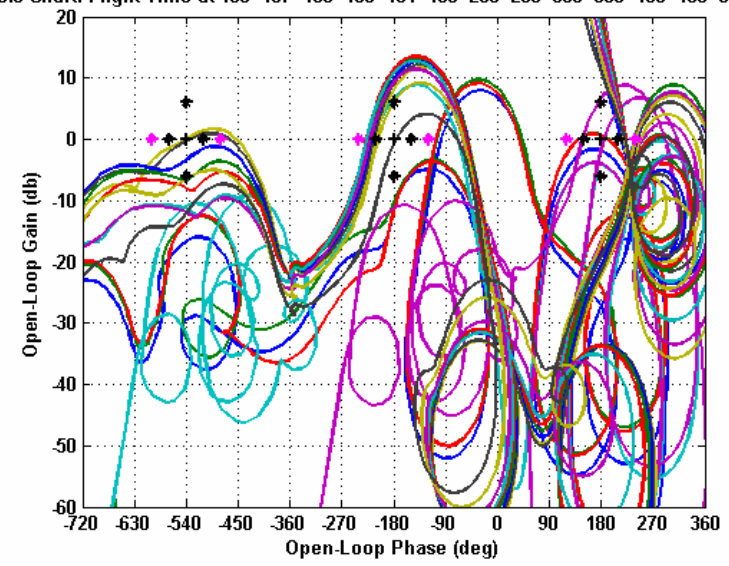

(b)

Figure 7. Upper Stage Flex Characteristics and Control Systems Without Bending Filters
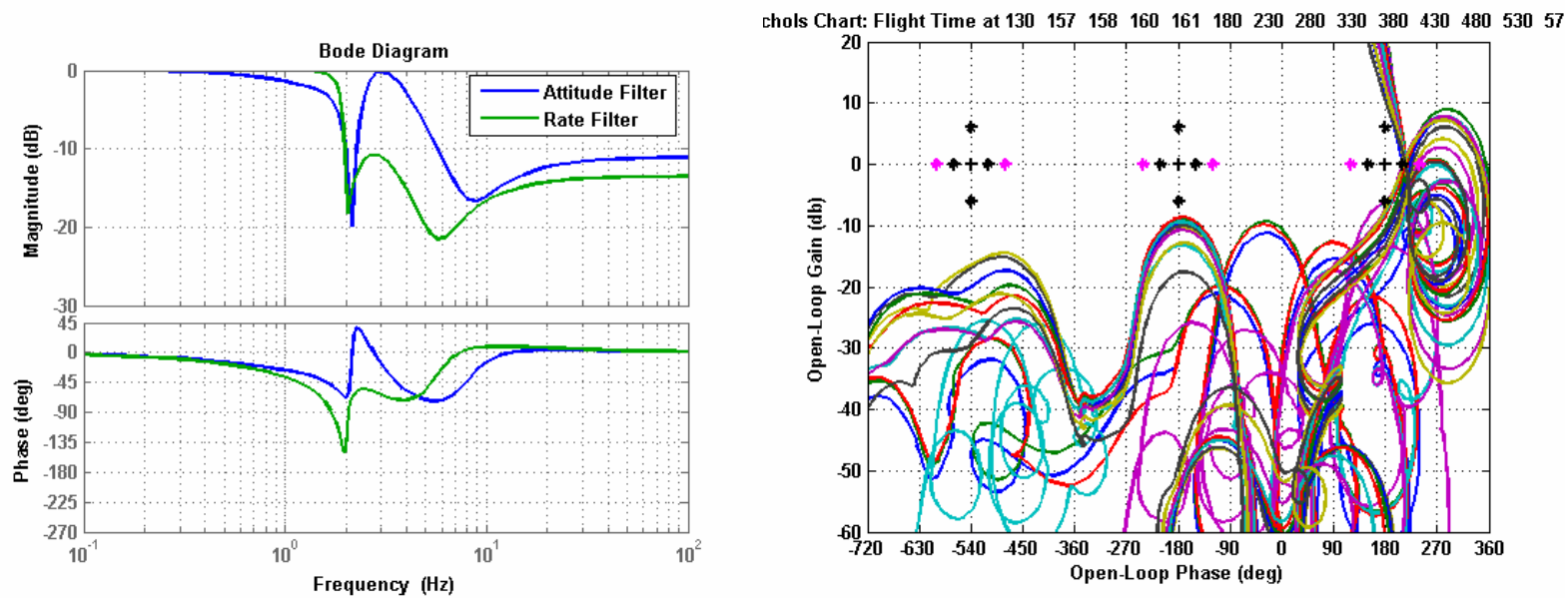

Figure 8. Nichols Chart of Upper Stage Nominal Control Systems with Final First Stage Filter 


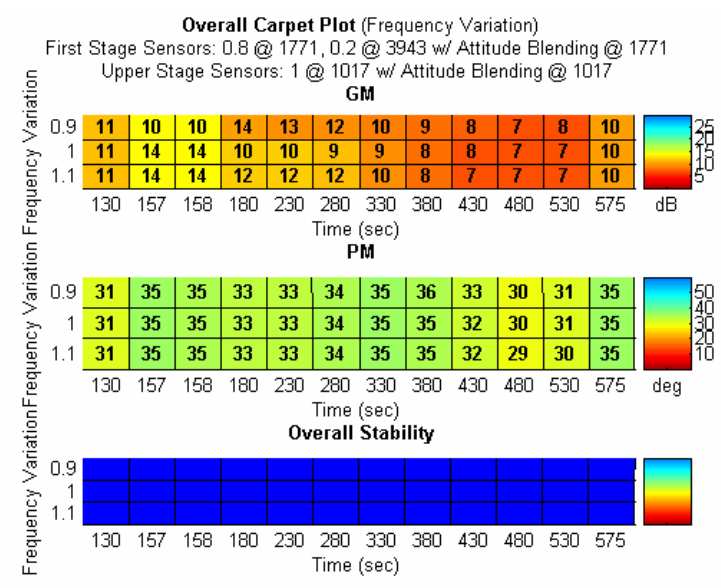

(b)

Mode 2 Carpet Plot (Frequency Variation) First Stage Sensors: 0.8@1771,0.2@3943 w/ Attitude Blending @ 1771

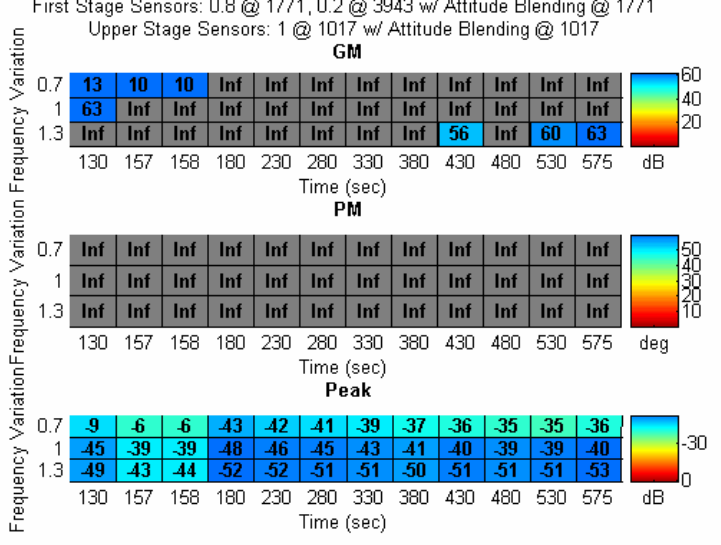

(d)

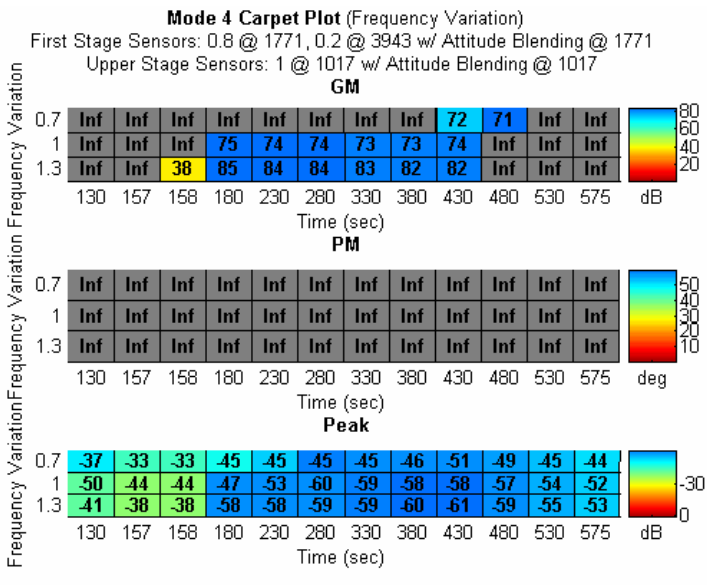

(e)

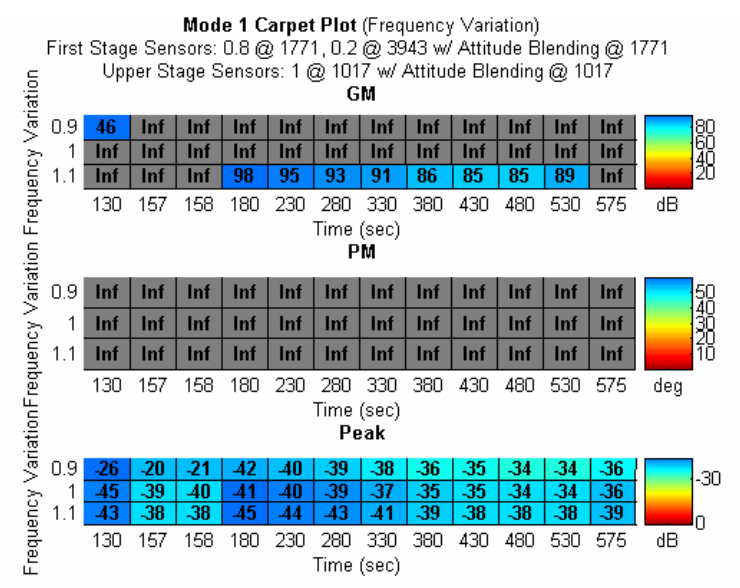

(b)

Mode 3 Carpet Plot (Frequency Variation) First Stage Sensors: 0.8@1771,0.2@3943w/ Attitude Blending@1771

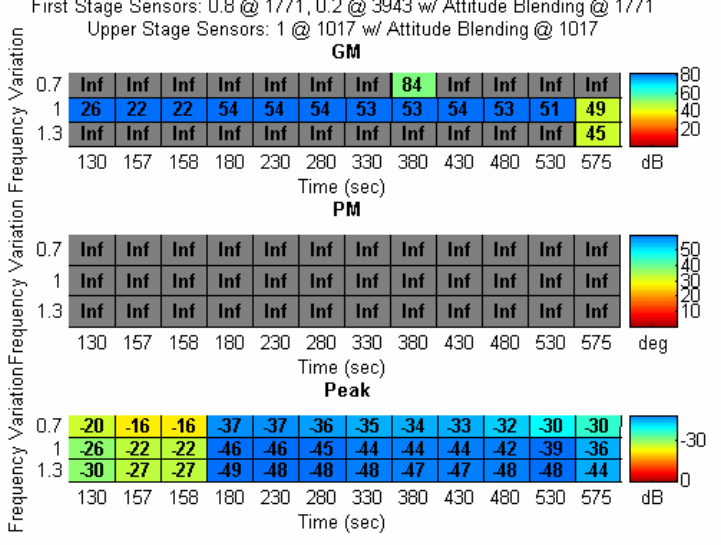

(d)

Mode 5 Carpet Plot (Frequency Variation)

First Stage Sensors: 0.8@1771,0.2@3943w/ Attitude Blending@ 1771

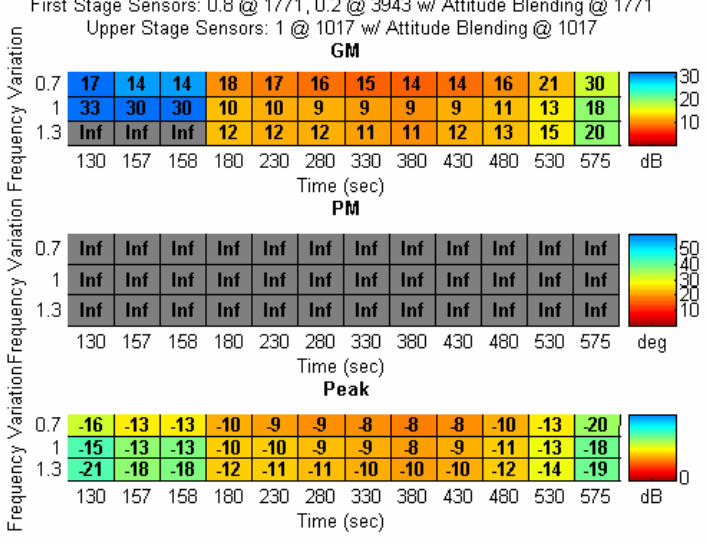

Figure 9. Robust Analysis Summary of Upper Stage Control Systems 


\section{Summary}

The Ares-I launch vehicle represents a unique challenging flex-body structural environment for control system design. This paper presents a design methodology employing numerical optimization to develop the Ares-I bending filters. The filter design methodology was based on a numerical constrained optimization approach to maximize stability margins while meeting performance requirements. The first stage bending filter design achieves stability by adding lag to the first structural frequency and hence phase stabilizes the first Ares-I flex mode while gain stabilizing the higher modes; the upper stage bending filter design gain stabilizes all the flex bending modes. The bending filter designs provided here have been demonstrated to provide stable first and second stage control systems in Draper Ares Stability Analysis Tool (ASAT).

\section{Acknowledgements}

Acknowledgments go here.

\section{References}

[1] Hall, R., Jang, J., Yang, L. and Bedrossian, N., “Ares I DAC2 Flight Control Design Concept Package,” Draper Laboratory Memo CLV GNC 07-015, September 26, 2007.

[2] Oppenheim, A. V, and Schafer, R. W., Digital Signal Processing, Prentice-Hall Company, Inc., Englewood Cliffs, New Jersey, 1975.

[3] Friedlander, B., and Porat, B, "The Modified Yule-Walker Method of ARMA Spectral Estimation," IEEE Transactions on Aerospace Electronic Systems, AES-20, No. 2, March 1984, pp. 158-173.

[4] Strum, R. D. and Kirk, D. E., First Principles of Discrete Systems and Digital Signal Processing, Addison-Wesley Publishing Company, Inc., New York, April 1989.

[5] Gresham, L., Mitchell, J., McDaniel, W., "Multivariable Control System Design Algorithm," Journal of Guidance and Control, Vol. 3, No. 4, July-August, 1980.

[6] Blackburn, T., Vaughan, D., "Application of Linear Optimal Control and Filtering Theory to the Saturn V Launch Vehicle," IEEE Transactions on Automatic Control, Vol. AC-17, No. 6, December 1971.

[7] Boyd, S. P., Linear Controller Design, Prentice-Hall, Inc., New Jersey, 1991.

[8] McGovern, L. K., A Constrained Optimization Approach to Control with Application to Flexible Structures, Massachusetts Institute of Technology, Massachusetts, June 1996. 
[9] Lintereur, B. V., Constrained H2 Design Via Convex Optimization with Applications, Master Thesis, Massachusetts Institute of Technology, Massachusetts, June 1998.

[10] Ninness, B. and Gustafsson, F., "A Unifying Construction of Orthonormal Bases for System Identification," IEEE Transactions on Automatic Control, vol. 42, no. 4, pp. 515521, April 1997.

[11] Jang, J., Bedrossian, N., Lee, A, Spanos, P., “A Constrained Optimization Approach for CMG Robust Flex Filter Design”, AIAA GN\&C Conference, August 2002.

[12] Jang, J., Lee, A., Bedrossian, N., Spanos, P., "Design of Robust Nash Game Theoretic Controllers with Time Domain Constraints," American Control Conference, 2003.

[13] Bedrossian, N., Jang, J., Alaniz, A., Johnson, M., Sebelius, K., Mesfin, Y., "International Space Station US GN\&C Attitude Hold Controller Design for Orbiter Repair Maneuver," AIAA GN\&C Conference, August, 2005.

[14] Postma, B., Jang, J., Bedrossian, N., Spanos, P., "Robust Constrained Optimization Approach for International Space Station Centrifuge Rotor Auto-Balancing Controller," AIAA GN\&C Conference, August, 2005.

[15] Jang, J., Bedrossian, N., Hall, R., Norris, L. H., Hall, C., Jackson, M., "Initial Ares-I Bending Filter Design," 30 ${ }^{\text {th }}$ AAS Guidance and Control Conference, February 2008.

[16] Jang, J., Tassell, C. V., Barrows, T., Hall, R., Bedrossian, N., Hall, C., “Ares Stability Analysis Tool," to be submitted to 2008 AIAA GNC Conference.

[17] Haussermann, W., Duncan, R.C, "Status of Guidance and Control Methods, Instrumentation, and Techniques as Applied to the Apollo Project", Agardograph 92, NASA Code ATSS-AD, October 1964.

[18] Frosch, J.A., Vallely, D.P., "Saturn AS-501/S-IC Flight Control System Design", Journal of Spacecraft, Vol. 4, No. 8, August 1967.

[19] Lominick, J., “SRB TVC System Design”, NASA MSFC memo EC25 (170-75), April 3, 1975.

[20] N. Bedrossian, R. Hall, J. Jang, R. Masterson, "CLV DAC 1 Analysis: First Stage Attitude Control System Bending Filter Design and Sensor Location Trade Studies", Draper Lab memo CLV GNC-06-002, July 14, 2006.

[21] Greensite, A. L., Analysis and Design of Space Vehicle Flight Control Systems, Spartan Book, New York, 1970.

[22] Rao, S. S., "Game Theory Approach for Multi-objective Structural Optimization," Computers \& Structures, Vol. 24, No. 1, 1987, pp. 119-127. 
[23] Ares I Guidance, Navigation, and Control System Design Document, NASA MSFC Memo CxP72069, August 31, 2007. 